\title{
CORRESPONDENCE
}

\section{Is lung function really a good parame- ter in evaluating the long-term effects of inhaled corticosteroids in COPD?}

\section{To the Editor:}

In a recent editorial in the European Respiratory Journal, VAN SCHAYCK [1] advocated the use of end-points other than forced expiratory volume in one second (FEV1) decline in the studies of inhaled corticosteroids (ICS) in chronic obstructive pulmonary disease (COPD). Since this view-point is heard increasingly often, especially from those in favour of the use of ICS in COPD, it seems worthwhile to review the basis for choosing FEV1 decline in the four recently completed largescale trials of ICS in COPD and to comment on the effect of ICS on other end-points in these trials.

Five to 10 yrs ago there was a genuine optimism regarding the use of ICS in COPD, not as symptomatic treatment but as a medication which could modify the natural history through decreasing the excess decline in FEV1 which has been the established hallmark of COPD since the classic study of FletCher et al [2]. The optimism came from both the asthma experience and the growing realization that inflammatory processes are involved in COPD, as expressed in the "Dutch hypothesis" [3, 4]. It was further fuelled by a number of studies indicating a possible beneficial effect of ICS in COPD [5-7]; however, some of these studies did not differentiate COPD from asthma and others were insufficiently powered or of too short duration to actually study a potential disease modifier in COPD. For these reasons it was considered appropriate to conduct large-scale long-term studies focusing on the effect of ICS on FEV1 decline in wellcharacterized patients with COPD.

The effects of ICS on FEV1 in the recent trials are wellknown and it seems sufficient to say that an initial effect is seen within 6 months and thereafter no significant effect on FEV1 decline is seen. Thus, most pulmonologists do not see ICS as a true modifier in COPD. This does not mean that ICS may have a role in COPD and we agree with vAN SCHAYCK [1] that other measures should be looked at. In our own study [8] no effect of ICS was seen on respiratory symptoms or exacerbations. It is worth noting that prevalence of respiratory symptoms actually declined over the study period in both groups, again underlining the necessity of the randomized controlled trial. In the European Respiratory Society Study on Chronic Obstructive Pulmonary Disease (EUROSCOP) publication [9] no data are given on the effect of ICS on secondary effect parameters but from several presentations we have been given the impression that no effect on symptoms and exacerbations was seen. From the Inhaled Steroids in Obstructive Lung Disease in Europe (ISOLDE) presentations we know that a modest but significant effect of ICS on exacerbations was found and that subsequent substratification indicates that this effect is almost entirely seen in subjects with an FEV1 $<1.25 \mathrm{~L}$. The effect on exacerbations translates into a clear and significant effect on health status measured with the St. George's Respiratory Health Questionnaire; we are not aware of an effect on respiratory symptoms. From second-hand knowledge of the results of the as yet unpublished Lung Health Study II, we believe that an effect on respiratory symptoms was seen as well as an effect on "nonscheduled physician visits".

From the above it is apparent that ICS do not modify the natural history of COPD by slowing the decline in FEV1 and that no consistent effects on other parameters have been seen although it seems likely that patients with severe COPD may benefit from treatment through reduction in exacerbations and thus an improvement in health status. It is desirable that the obtained data are used optimally and for this purpose a meta-analysis may be appropriate as it could better look at the effect of ICS over almost the entire spectrum of severity of COPD.

In conclusion, we believe that we should acknowledge the value of results gained from the recent long-term studies of inhaled corticosteroids on forced expiratory volume in one second decline in chronic obstructive pulmonary disease and appreciate the directions pointed out and the new hypotheses raised from these data. All studies had specific aims and it is our belief that the respiratory society was actually obliged to these kind of studies for the sake of providing proper evidence for decision making. So far, only the Inhaled Steroids in Obstructive Lung Disease in Europe study has documented a long-term beneficial effect of inhaled corticosteroids on health status and before jumping to preliminary strong conclusions we should await further studies already ongoing as part of the trials of combinations of inhaled corticosteroids and long-acting bronchodilators in chronic obstructive pulmonary disease.

J. Vestbo, P. Lange

Dept of Respiratory Medicine 223, Hvidovre University Hospital, DK-2650 Hvidovre, Denmark. Fax: 4536323716.

\section{References}

1. van Schayck CP. Is lung function really a good parameter in evaluating the long-term effect of inhaled corticosteroids in COPD? Eur Respir J 2000; 15: 238-239.

2. Fletcher CM, Peto R, Tinker CM, Speizer FE. The Natural History of Chronic Bronchitis and Emphysema. Oxford, Oxford University Press, 1976.

3. Orie NGM, Sluiter HJ, de Vries K, Tammeling GJ, Witkop J. The host factor in bronchitis. In: Orie NGM, Sluiter HJ, eds. Bronchitis: an international symposium. Assen, the Netherlands, Royal van Gorcum, 1961.

4. Vestbo J, Prescott E. An update on the Dutch hypothesis and chronic respiratory disease. Thorax 1998; 53: Suppl. 2, S15S19.

5. Kerstjens HAM, Brand PLP, Hughes MD, et al. A comparison of bronchodilator therapy with or without inhaled corticosteroid therapy for obstructive airways disease. $N$ Engl J Med 1992; 327: 1413-1419.

6. Renkema TEJ, Schouten JP, Köeter GH, Postma DS. Effects of long-term treatment with corticosteroids in COPD. Chest 1996; 109: 1156-1162. 
7. Dompeling E, van Schayck CP, van Grunsven PM, et al. Slowing the deterioration of asthma and chronic obstructive pulmonary disease observed during bronchodilator therapy by adding inhaled corticosteroids: a 4 year prospective study. Ann Intern Med 1993; 118: 770-778.

8. Vestbo J, Sørensen T, Lange P, Brix A, Torre P, Viskum K. Long-term effect of inhaled budesonide in mild and moderate chronic obstructive pulmonary disease - a randomised, control-led trial. Lancet 1999; 353: 1819-1823.

9. Pauwels RA, Löfdahl C-G, Laitinen LA, et al., for the European Respiratory Society Study on Chronic Obstructive Pulmonary Disease. Long-term treatment with inhaled budesonide in persons with mild chronic obstructive pulmonary disease who continue smoking. N Engl J Med 1999; 340: 1948-1953.

\section{From the author:}

I would like to thank J. Vestbo and P. Lange for their comments on my recent editorial [1]. The purpose of this editorial was not to "jump to preliminary strong conclusions on the effects of inhaled corticosteroids (ICS) on health status". I completely agree with their conclusion that ICS do not modify the natural history of chronic obstructive pulmonary disease (COPD), which was actually the message of the editorial. This conclusion is based on two important aspects. Firstly, the available data in COPD show that ICS only have an effect during the first 6 months and not on the subsequent decline in lung function. As fig. 1 shows, this indicates that when we extrapolate these data, a considerable gain in time is obtained before reaching a very poor forced expiratory volume in one second (FEV1) in asthma. However, this is not the case in COPD. Secondly, the age at which COPD becomes apparent and is actually diagnosed is normally much older than the age at which asthma does. This means that patients with asthma normally have a much longer period to benefit from the use of inhaled steroids than patients with COPD. What is the real benefit of having 50 $\mathrm{mL}$ more FEV1 when a COPD patient is 70 yrs old? For these patients it is much more relevant to have less exacerbations or to have a better health function. There are some indications that ICS might have an effect on these aspects in severe COPD, irrespective of their effect on lung function [2]. Therefore, I advocated in my editorial not to focus any more merely on the effects on lung function but to study the effects of drug (and nondrug) treatment on exacerbations and functional status and to develop reliable instruments which measure these parameters and are also easily applicable in daily medical care.

It should be emphasized that the data in the figure are an extrapolation of the 4-yr study of Dompeling et al. [3] in which patients with COPD or with asthma were studied for 2 yrs not using inhaled steroids followed by 2 yrs using inhaled steroids. The relatively pronounced decline in patients with

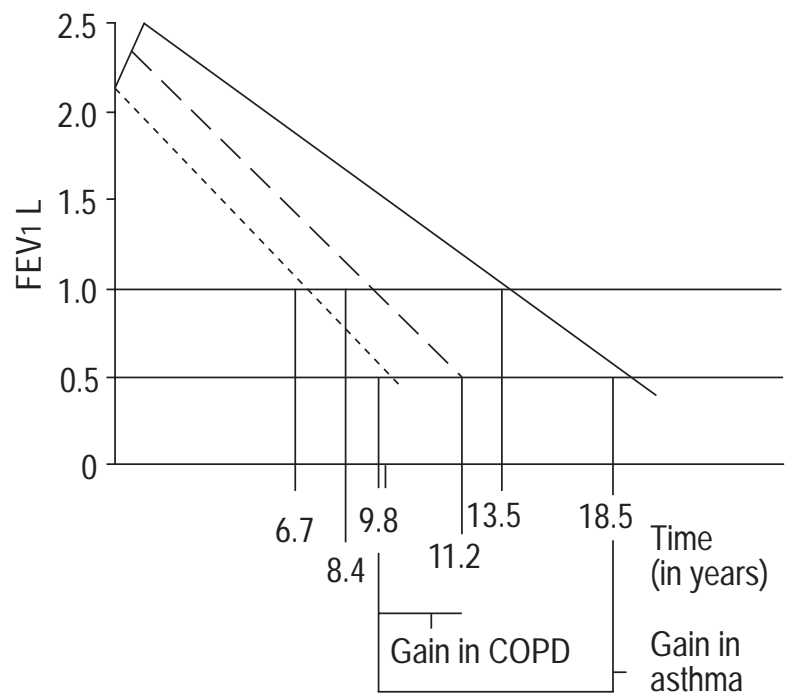

Fig. 1. - A theoretical comparison between the effects with and without inhaled corticosteroids until the development of severe airflow limitation in asthma and chronic obstructive pulmonary disease (COPD). ----: asthma and COPD without the use of corticosteroids; - - - COPD with the use of corticosteroids; — - asthma with the use of corticosteroids. FEV1: forced expiratory volume in one second. (Modified from [3]).

asthma not using inhaled steroids $\left(>100 \mathrm{~mL} \cdot \mathrm{yr}^{-1}\right)$, is much more than observed elsewhere [4] and clearly indicates the undertreatment of this group of asthmatic patients.

\section{C.P. van Schayck}

Dept of General Medicine, University of Maastricht, Maastricht, the Netherlands. Fax: 31433619344.

\section{References}

1. van Schayck CP. Is lung function really a good parameter in evaluating the long-term effect of inhaled corticosteroids in COPD? Eur Respir J 2000; 15: 238-239.

2. Calverley PM. Re-assessing the evidence about inhaled corticosteroids in chronic obstructive pulmonary disease. Thorax 1999; 54: 3-4.

3. Dompeling E, van Schayck CP, van Grunsven PM, et al. Slowing the deterioration of asthma and chronic obstructive pulmonary disease observed during bronchodilator therapy by adding inhaled corticosteroids: a 4 year prospective study. Ann Intern Med 1993; 118: 770-778.

4. Burrows B, Bloom JW, Traver GA, Cline MG. The course and prognosis of different forms of chronic airways obstruction in a sample from the general population. $N$ Engl J Med 1987; 317: 1309-1314. 